\title{
Effects of Plant Leaf Extract against Colletotrichum gloeosporioides (Penz) Sac. Causing Post-Harvest Disease of Papaya
}

\author{
Rahul Ravneel Prasad ${ }^{1} \&$ Anamika $^{1}$ \\ ${ }^{1}$ Department of Agriculture, Fiji National University, Fiji Island \\ Correspondence: Anamika, Department of Agriculture, Fiji National University, Fiji Island. E-mail: \\ anamika_bhu01@rediffmail.com
}

Received: February 3, 2015 Accepted: March 5, 2015 Online Published: April 15, 2015

doi:10.5539/jas.v7n5p195 URL: http://dx.doi.org/10.5539/jas.v7n5p195

\begin{abstract}
The antifungal activity of selected weed and other plants leaf extract prepared in distilled water and ethanol were tested against anthracnose, the post-harvest disease of papaya (Carica papaya L.) caused by Colletotrichum gloeosporioides. The result from the experiment proved that ethanol leaf extract of weed plant, Lantana camara L.possess significant fungicidal effect on the radial growth of C. gloeosporioides followed by lemon and avocado leaf extract while Mikania micrantha Kunth, Sphagneticola trilobata (L.) Pruski and Cyperus rotundus L. leaf extract gave an insignificant inhibitory effect on the radial growth the fungus. The result of this study showed that Lantana camara leaf extract has the potential antifungal compound to control C. gloeosporioides which is the casual organism of papaya anthracnose.
\end{abstract}

Keywords: Lantana camara, C. gloeosporioides, Carica papaya

\section{Introduction}

Papaya also known as pawpaw (Carica papaya) is considered as one of the most popular fruits among the millions of people in the tropical and subtropical area due to it taste, nutrition value and medicinal use. It is the fruit that gives high income return to the farmers in Fiji since it is exported to Australia, New Zealand and it is also sold in local markets around Fiji Islands. The fruits are sensitive to decay, low temperature and general fruit perish ability due to the rapid ripening and softening limits the storage, handling and transport potential.

Anthracnose caused by $C$. gloeosporioides, is the major postharvest disease of papaya in all papaya producing areas in Fiji and as well all around the world. In general, the fungus initiates infection as soon as flowering starts and stays in latent form until the postharvest environment conditions favour colonization of fruit tissue. According to Coursey, postharvest losses of approximately $40-100 \%$ have been generally reported in papaya in developing countries (Rahman et al., 2011). Synthetic fungicides are currently used as the primary means for the control of plants diseases which are used at pre-harvest or post-harvest treatments acting as the main approach to reduce losses from anthracnose. However, their use is increasingly restricted due to environmental and public concerns due to its application as alone, combined in mixtures or applied separately in sequence. So, the alternative control methods are needed because of the negative effects of synthetic chemicals which increase the risk of high levels of toxic residues, which is particularly serious, since papaya fruits are consumed in relatively short time after harvest. Bioactive products of plants have less negative effect on the environment and are safe for mammals, other non-target organisms and for the control of postharvest disease than synthetics. A number plant species have been reported to possess natural substances that are toxic to many fungi causing plant disease. Rahman et al. (2011) indicated that Jatropha curcas has the antifungal activity against anthracnose of papaya. Similarly, Banos et al. (2003) indicated that plant leaf extract has antifungal against $C$. gloeosporioides. Papaya anthracnose is one of the major diseases of crop in Fiji. Hence, the study was carried out with the objective of determining the in vitro effect of plant extract on the radial growth of $C$. gloeosporioides.

\section{Materials and Methods}

\subsection{Isolation of Target Pathogen}

C. gloeosporioides was isolated from papaya fruits showing anthracnose lesions. An isolate of the pathogen grown as pure culture and was maintain in PDA (Potato dextrose agar) medium which was used as stock culture throughout the study. 


\subsection{Inoculum Disc}

Seven days old culture of the test fungus was used for the preparation of inoculum disc of $5 \mathrm{~mm}$ in diameter.

\subsection{Sample Collection}

The potential plant extract were selected from a screening of weed and different plants species. The leaf samples were collected from Koronivia Research Farm (Fiji Islands). The experiment was conducted in the science laboratory of the College of Agriculture, Fisheries and Forestry (Fiji National University).

$\begin{array}{ll}\text { Common Name } & \text { Scientific Name } \\ \text { Lantana } & \text { Lantana camara } \\ \text { Mile-a-minute } & \text { Mikania micrantha } \\ \text { Wedelia } & \text { Sphagneticola trilobata } \\ \text { Nut grass } & \text { Cyperus rotundus } \\ \text { Mango } & \text { Mangifera indica } \text { L. } \\ \text { Papaya } & \text { Carica papaya } \\ \text { lemon } & \text { Citrus Limon L. } \\ \text { Avocado } & \text { Persea Americana Mill. }\end{array}$

\subsection{Plant Leaf Extracts Preparation}

Fresh Plants leaves was selected and were washed thoroughly 2-3 times with running tap water, followed by distilled water, and then air dried. An ethanol and aqueous extract was prepared by blending $50 \mathrm{~g}$ of the selected plant leaves in $50 \mathrm{ml}$ ethanol and distilled water (DW) each in a blender for 10 minutes. The macerate was filtered through double layered musclin cloth and centrifuged at $4000 \mathrm{rpm}$. The supernatant was filtered through whatmann No. 1 filter paper and sterilized at $120^{\circ} \mathrm{C}$ for 30 minutes. The plant extract was preserved aseptically in bottle at $5{ }^{\circ} \mathrm{C}$ until further use (Satish et al., 1999).

\section{5 in vitro Evaluation of Fungicidal Activity of Plant Extract}

The inhibitory effect of plant extract for their antifungal potentials against $C$. gloeosporioides causing papaya anthracnose was done by food poison technique (Nene \& Thapliyal, 1993) method. A volume of $0.5 \mathrm{ml}$ of each concentration was aseptically poured into the petriplate followed by the addition of $9.5 \mathrm{ml}$ of melted PDA and was mixed gently to achieve thorough mixing of the contents. In the control set, no extract was used. After the solidification of the media, one inoculum disc of the test fungus was aseptically inoculated upside down at the centre of the petriplate and incubated at $25^{\circ} \mathrm{C}$. The average radial growths of the fungal colonies were measured on the 7th day of incubation. The treatments were as follows:

T0 (Colletotrichum. gloeosporioides)

$\mathrm{T} 1$ (C. gloeosporioides + mile- a- minute leaf extract)

T2 (C. gloeosporioides + lantana leaf extract)

T3 (C. gloeosporioides + nut grass leaf extract)

$\mathrm{T} 4$ (C. gloeosporioides + mango leaf extract)

T5 (C. gloeosporioides + papaya leaf extract)

T6 (C. gloeosporioides + lemon leaf extract)

T7 (C. gloeosporioides + wedelia leaf extract)

T8 (C. gloeosporioides + Avocado leaf extract)

Each treatment was replicated four times and the reading was taken and data were statistically analysed at $5 \%$ CD.

\section{Results and Discussion}

All the extracts showed inhibition effects on the growth of the test fungus (Table 1). The fungicidal activity of different weed plant and plant leaf extract in ethanol and distilled water were used to inhibit the growth of Colletotrichum gloeosporioides. The extracts of Lantana camara were found to be most effective for the control of the test fungus. The plant species showed reasonable effects among themselves. Relative variation in the content of active chemicals in the extracts was speculated to be one of the evident reasons, which was followed 
by T6 (Lemon leaf), T8 (Avocado leaf) and T5 (Papaya leaf) while the other T4 (mango leaf), T7 (wedelia leaf) and T3 (nut grass leaf) shows the least inhibition as compared to control. The radial growths of the replication were found significantly different among each other. Similar observations were also reported by Ademe et al. (2013) who tested the plant extract against the radial growth of Colletotrichum gloeosporioides and found that extract of Lantana camara resulted in the highest inhibition against Colletotrichum gloeosporioides. The report by Banos et al. (2002), Richa et al. (2012) who tested the plant extract against the radial growth of Colletotrichum gloeosporioides and found that Citrus Limon, Persea americana and Carica papaya totally inhibited growth of Colletotrichum gloeosporioides. Plant extract showing antimicrobial effect have been proved against several diseases (Anamika \& Simon, 2011). Similarly Lucy et al. (2010) reported that the leaf crude extracts of Alpinia galanga exhibited effectiveness against $C$. gloeosporioides and should be considered for further evaluation.

\section{Conclusion}

Effect of plant extract on C. gloeosporioides showed promising prospect for the utilization of plant extract in postharvest disease control and Lantana camara can be used as a ecofriendly control method against the post-harvest disease of papaya. Further studies on the isolation and characterization of the active (Antifungal) compounds are needed for field experiment in order to gain information about the effectiveness of the extract tested against fungal disease. The results will be important since the field studies will reveal the efficacy of the leaf extract in controlling the fungi as they interact with environmental factors.

Table 1. In vitro effect of weed and plant species leaf extract in ethanol and distilled water on the radial growth of C. gloeosporioides

\begin{tabular}{lll}
\hline Treatments & $\begin{array}{l}\text { Radial growth (7 DAI) } \\
\text { (Leaf extract in ethanol) }\end{array}$ & $\begin{array}{l}\text { Radial growth (7DAI) } \\
\text { (Leaf extract in DW) }\end{array}$ \\
\hline T0 (Control) & 3.78 & 3.82 \\
T1 (mile- a- minute leaf extract) & 3.65 & 3.65 \\
T2 (lantana leaf extract) & 0.98 & 0.96 \\
T3 (nut grass leaf extract) & 3.63 & 3.65 \\
T4 ( mango leaf extract) & 3.34 & 3.38 \\
T5 (papaya leaf extract) & 1.35 & 1.58 \\
T6 (lemon leaf extract) & 1.02 & 1.03 \\
T7 (wedelia leaf extract) & 3.37 & 3.41 \\
T8 (Avocado leaf extract) & 1.11 & 1.08 \\
C.D. at 5\% & 1.06 & 0.125 \\
\hline
\end{tabular}

Note. DAI: Days after inoculation.

\section{References}

Anamika, \& Simon, S. (2011). Inhibitory effect of botanical extracts against Alternaria alternata of Aloe Vera dry rot. Archieves of Phytopathology and Plant Protection, 44(15), 1462-1466. http://dx.doi.org/10.1080/03235408.2010.505784

Banos, S. B., Lopes, M. H., Molina, E. B., Wilson, C. L. (2003). Effects of chitosan and plant extracts on growth of C. gloeosporioides, anthracnose levels and quality of papaya fruit. Crop Protection, 22(9), 1087-1092. http://dx.doi.org/10.1016/S0261-2194(03)00117-0

Lucy, J., Umi, K. Y., \& Rosimah, N. (2010). The effect of herbal plant extracts on the growth and sporulation of Colletotrichum gloeosporioides. Journal of Applied Biosciences, 34, 2218-2224.

Nene, Y. L., \& Thapliyal, P. N. (1993). Evaluation of fungicides in fungicides in plant diseases control (3rd ed., p. 331). New Delhi: Oxford and INH publishing Co. pvt. Ltd.

Rahman, M., Ahmad, S. H., Mohamed, M. T. M., \& Rahman, M. Z. (2011). Extraction of Jatropha curcas fruit for antifungal activity against anthracnose (C. gloeosporioides) of papaya. African Journal of 
Biotechnology, 10(48), 9796-9799.

Richa, S., Manindra, M., Prashant, S., Syed, Z. H., Sanjay, G., Irshita, B., ... Rajendra, D. (2012). Chemical composition and antibacterial properties of the essential oil and extracts of Lantana camara Linn. from Uttarakhand (India). Asian Pacific Journal of Tropical Biomedicine, 2(Supplement 3), 1407-1411. http://dx.doi.org/10.1016/S2221-1691(12)60426-2

Rahman, M., Ahmad, S. H., Mohamed, M. T. M., \& Rahman, M. Z. (2011). Extraction of Jatrophacurcas fruit for antifungal activity against anthracnose (Colletotrichum gloeosporioides) of papaya. African Journal of Biotechnology, 10(48), 9796-9799.

Satish, S., Raveesha, K. A., \& Janardhana, G. R. (1999). Antibacterial activity of plant extracts on phytopathogenic Xanthomonas campestris pathovars. Letters in Applied Microbiology, 28, 145-147. http://dx.doi.org/10.1046/j.1365-2672.1999.00479.x

\section{Copyrights}

Copyright for this article is retained by the author(s), with first publication rights granted to the journal.

This is an open-access article distributed under the terms and conditions of the Creative Commons Attribution license (http://creativecommons.org/licenses/by/3.0/). 